\title{
Sewage and environmental impacts on rocky shores: necessity of identifying relevant spatial scales
}

\author{
M. J. Bishop*, A. J. Underwood, P. Archambault** \\ Centre for Research on Ecological Impacts of Coastal Cities, Marine Ecology Laboratories, A11, University of Sydney, \\ New South Wales 2006, Australia
}

\begin{abstract}
The concentration of contaminants usually decreases with increasing distance from a point-source disturbance, so sampling to detect ecological impacts is usually done at 1 spatial scale, often at regular intervals from the point of discharge. There is, however, concern that the choice of an inappropriate scale will cause failure to detect impacts or failure to identify and estimate the size of impacts. In this study, the putative impact of a shoreline sewage outfall on the abundance of green ephemeral algae and gastropods was sampled at 2 spatial scales (tens of metres and several kilometres from the point of discharge) in order to determine whether the ecological impact of effluent was comparable across these, as would be expected if the abundance of species follows the gradient of contaminants. Such sampling also enabled the putative impact of this outfall on the spatial variability of taxa to be examined at 3 spatial scales: (1) among quadrats in the site with the outfall compared to variance among quadrats in other sites on the shore with the outfall; (2) among quadrats in non-outfall sites on the shore with the outfall compared with variance among quadrats in sites on control shores; (3) between non-outfall sites on the shore with the outfall in comparison to among sites on the control shores. A greater abundance of Enteromorpha spp. was found close to the outfall than further away at both spatial scales. Patterns in the abundance of many other taxa differed between the 2 spatial scales of sampling. The density of the limpet Patelloida latistrigata was much greater close to than far from the outfall, when considered on a large spatial scale. At the smaller scale among sites on a single shore, the impact was completely reversed-densities were much smaller close to than away from the outfall. Variances, like abundances, did not always follow the gradient of contaminants and different patterns were often seen at different spatial scales. Thus, putative impacts should be sampled on multiple spatial scales using nested sampling designs. Where this is not possible, the spatial scale at which an impact might be detected or interpreted needs to be clearly stated because the generalisation that a disturbance has a similar impact at all spatial scales relevant to the population being studied cannot be made without explicit tests.
\end{abstract}

KEY WORDS: Spatial scale · Ecological impact $\cdot$ Point-source disturbance $\cdot$ Gradient $\cdot$ Contaminant . Sewage outfall $\cdot$ Abundance $\cdot$ Variance

\section{INTRODUCTION}

Environmental gradients are important in determining the structure of assemblages. Patterns of abun-

\footnotetext{
*E-mail: mbishop@bio.usyd.edu.au

**Present address: Environmental Sciences Division, Regional Oceans and Environment Branch, Fisheries and Oceans Canada, Institut Maurice-Lamontagne, 850, Route de la Mer, CP 1000, Mont-Joli, Québec G5H 3Z4, Canada
}

dance and diversity of species, the size of food webs and the complexity of ecological interactions are often associated with gradients in elevation, water-flow and salinity (see Menge \& Olson 1990). In marine habitats, gradients in contaminants are commonly found away from point-source disturbances (Keough \& Black 1996, Raimondi \& Reed 1996). The dissipation of contaminants by waves and their dilution with seawater increases with increasing distance from a point of discharge. Thus, gradients of contamination are super- 
imposed on (and interact with) natural, ecological gradients.

In the case of sewage outfalls, gradients in the temperature of the water, salinity and concentrations of nutrients and heavy metals may result from the discharge of effluent. Such properties of sewage effluent have been widely documented as affecting intertidal organisms. They may reduce the diversity of intertidal flora and fauna compared to non-impacted, control locations (Borowitzka 1972, May 1985, Fairweather 1990, López Gappa et al. 1990) and may result in assemblages dominated by only a few species of macroalgae (Borowitzka 1972, Littler \& Murray 1975, May 1985). In addition, the spatial and temporal variability of abundances of species may be increased by effluent (Fairweather 1990). Increased variability among samples has been hypothesised to be a general feature of stressed environments (Warwick \& Clarke 1993), but this is not always so (Chapman et al. 1995).

Impacts of shoreline sewage outfalls and other pointsource disturbances on the ecology of intertidal organisms are often believed to follow gradients in the concentration of contaminants, decreasing with increasing distance from a point of discharge. Consequently most studies have sampled putative impacts from pointsources at only 1 spatial scale and at regular intervals from the point of discharge (e.g. May 1985, Foe \& Knight 1987, López Gappa et al. 1990, Zmarzly et al. 1994, but see Chapman et al. 1995 for an example of a study where sampling was on multiple spatial scales). Contamination (the presence of unnatural chemicals) is not, however, synonymous with pollution (i.e. effects of, or responses to, such contamination: see Intergovernmental Oceanographic Commission, UNESCO 1986). Gradients of contaminants are often poorly matched with ecological gradients in abundances (or other features) of organisms (Keough \& Black 1996, Raimondi \& Reed 1996). Sampling at regular intervals from a disturbance is therefore not necessarily appropriate.

Although few studies have examined a single ecological process at more than 1 spatial scale (see Aronson 1994, Ward \& Saltz 1994), the extrapolation of results from 1 scale to another, without explicit sampling of each, is widespread (Wiens 1989, Levin 1992). In the case of ecological impacts, the absence of any effect at 1 spatial scale may lead to the false conclusion that there is no effect of the disturbance at any scale. Since the perception of patterns and processes is largely determined by the scale at which they are measured (e.g. Dayton \& Tegner 1984, Wiens 1989, Levin 1992), such inferences cannot always be made safely. While a small number of studies have sampled putative impacts from point-source disturbances on multiple spatial scales (usually locations and sites within locations) in order to estimate the variation at a spatial scale of interest (e.g. Chapman et al. 1995) or to determine the spatial extent of an impact (e.g. Inglis \& Lincoln Smith 1994), none appears to have adopted such sampling designs to determine whether an impact is consistent across scales.

In this study, the putative impact of a shoreline sewage outfall on the abundance of intertidal green ephemeral algae and gastropods is examined at 2 spatial scales - among shores and among sites on a single shore. The potential impact on the spatial variability of abundances of organisms was examined at 3 spatial scales to test the hypothesis that impacts would be comparable across the various scales, as would be expected if the size or direction of an impact is related to the gradient of decreasing contamination away from the point of discharge.

\section{MATERIALS AND METHODS}

Study sites. The Potter Point sewage outfall is located on the Kurnell Peninsula, approximately $25 \mathrm{~km}$ south of Sydney, New South Wales, Australia (151 $12^{\prime} 54^{\prime \prime} \mathrm{E}, 34^{\circ} 02^{\prime} 36^{\prime \prime} \mathrm{S}$; Fig. 1). Throughout the study, primary-treated effluent was discharged from the outfall at a depth of $6 \mathrm{~m}$ and at an average dryweather rate of $54 \mathrm{Ml} \mathrm{d}^{-1}$ (Sydney Water 1998). 2 rocky shores with similar substrata and exposure to waves as at Potter Point were selected as control locations. These were Cape Solander $(3.9 \mathrm{~km}$ north of the point of discharge at $151^{\circ} 13^{\prime} 54^{\prime \prime} \mathrm{E}, 34^{\circ} 01^{\prime} 12^{\prime \prime} \mathrm{S}$ ) and Yena Gap (2.5 km north at $151^{\circ} 13^{\prime} 48^{\prime \prime} \mathrm{E}, 34^{\circ} 01^{\prime} 00^{\prime \prime} \mathrm{S}$; Fig. 1). These measured any impacts at the large scale of whole shores several kilometres apart. No suitable control locations were found to the south of the outfall. Assemblages further than $400 \mathrm{~m}$ from this outfall have previously been described as unaffected by the discharge of effluent (Fairweather 1990). There is evidence that currents flow in each direction from the outfall, but are directed offshore by a rocky point north of the outfall (K. Banwell pers. comm.).

At each location, three $5 \times 5 \mathrm{~m}$ sites were haphazardly selected on the midshore, above a conspicuous belt of the tunicate Pyura stolonifera. On the shore with the outfall, 1 site was located immediately adjacent to the point of discharge ('Outfall site') and the other 2 at least $30 \mathrm{~m}$ away ('Other sites') to sample at a smaller spatial scale, i.e. tens of metres from site to site within a shore (Fig. 1). The 2 other sites at Potter Point were located to the south of the point of discharge because there was no suitable midshore habitat immediately to the north.

Sampling methods. The 3 locations were sampled in March (Time 1) and May (Time 2) 1999 during low 
tides. Cover of individual and total species of green ephemeral algae was estimated using 100 intersection points in a $0.5 \times 0.5 \mathrm{~m}$ quadrat. Green ephemeral algae were defined as members of the division Chlorophyta, with a relatively simple thallus, a short life-cycle $(<1 \mathrm{yr})$ and potential for rapid growth (see Santelices 1990). Four quadrats were placed randomly in each site and the number of intersection points under which green ephemeral algae were present was recorded as the cover of canopy. The canopy-forming species were then moved aside to reveal understorey species and bare substratum. Using this method, the maximal total cover in a quadrat was $200 \%$ (100\% canopy and 100\% understorey). Algae were only identified to genera because of difficulties in distinguishing amongst species in the field.

The abundance of gastropods was estimated using the same randomly positioned quadrats. Each species of gastropod was counted in five $4.5 \times 4.5 \mathrm{~cm}$ squares in the quadrat. Sub-sampling was done because numbers of limpets were very large (up to 6000 ind. $\mathrm{m}^{-2}$ ).

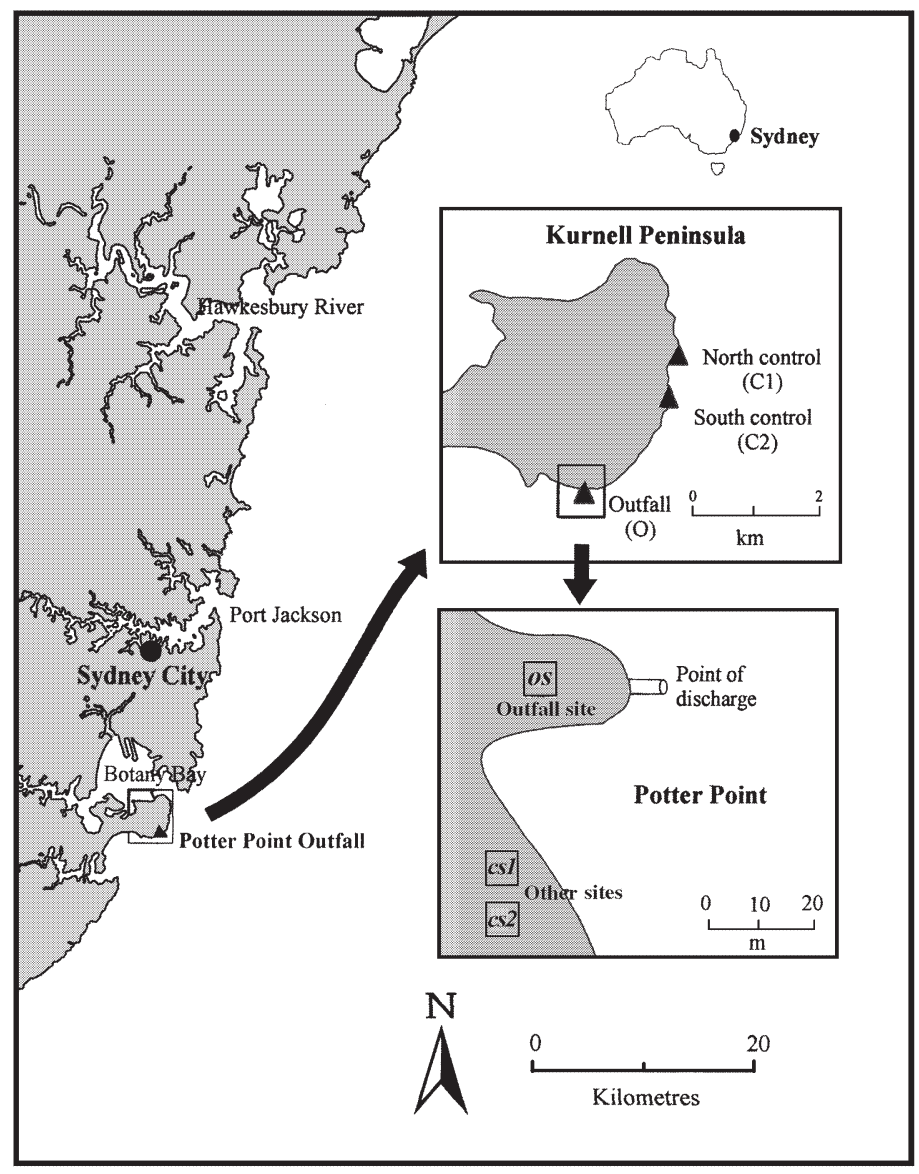

Fig. 1. Map of the Sydney coast showing the position of the Potter Point sewage outfall and control locations and sites at the 2 spatial scales sampled
Asymmetrical analyses of variance (see Underwood $1992,1993,1994)$ were used to compare the density of species at a single outfall to multiple control locations. At the smaller spatial scale, densities were compared between the single outfall site and the other 2 sites on the shore with the outfall. At the larger spatial scale, densities were compared among shores. Thus, Potter Point (with the outfall) was compared with the 2 control locations. For each time of sampling, spatial variability in abundances of selected taxa was compared in 3 ways: (1) variance among quadrats in the site with the outfall compared to variance among quadrats in the other sites on the shore with the outfall; (2) variance among quadrats in non-outfall sites at Potter Point compared with variance among quadrats in sites on control shores; (3) variance between sites on the shore with the outfall in comparison to variance among sites on the control shores.

The first of these is derived from the model that there is only a localised impact of the outfall (or a greater impact immediately around the outfall) that can influence variance among quadrats. The hypothesis tested is, therefore, that variance among quadrats in the site at the outfall will differ from that in sites tens of metres away.

The second considers the model that any impact is at a larger scale, large enough to affect variances across the whole shore where there is an outfall. In this case, variance among quadrats in sites where there is no outfall (i.e. on control shores) will differ from that between sites at Potter Point that are tens of metres away from the outfall.

The final comparison is again based on the larger-scale model (impacts affect variation across the whole shore), but at a larger spatial scale, from site to site (tens of metres), not quadrat to quadrat (metres apart). The hypothesis tested is that variation in abundances of taxa will not be the same between sites on a shore with an outfall as the variation among sites on shores where there is no outfall.

In some analyses, data had heterogeneous variances (determined by Cochran's test) and could not be stabilised by transformation. Given that analysis of variance is relatively robust to heterogeneous variances (Box 1953, Underwood 1997), particularly if there are many independent estimates of variance, untransformed data were analysed.

\section{RESULTS}

Four taxa of green ephemeral algae (Chaetomorpha spp. Kützing, Cladophora spp. Kützing, 
LOCATIONS

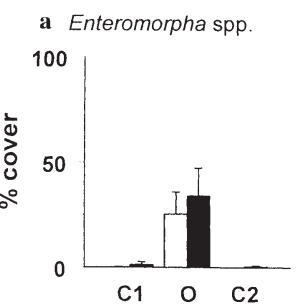

b Ulva spp.

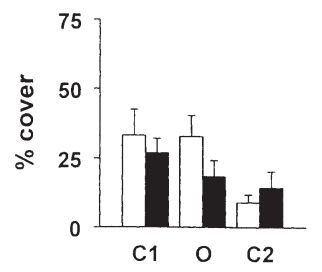

c Patelloida latistrigata

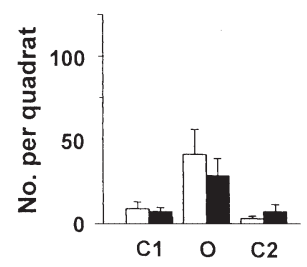

SITES (OUTFALL)
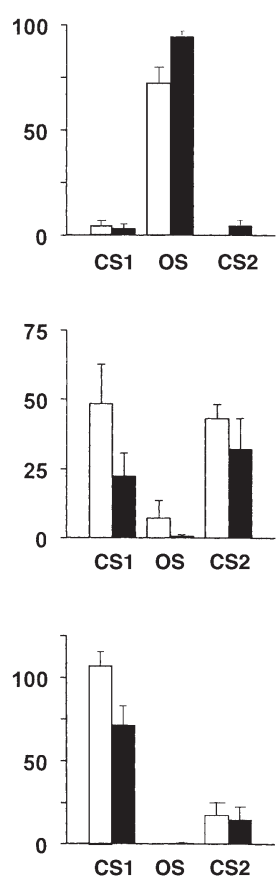

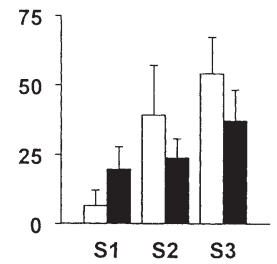

SITES (CONTROL 1)

SITES (CONTROL 2)
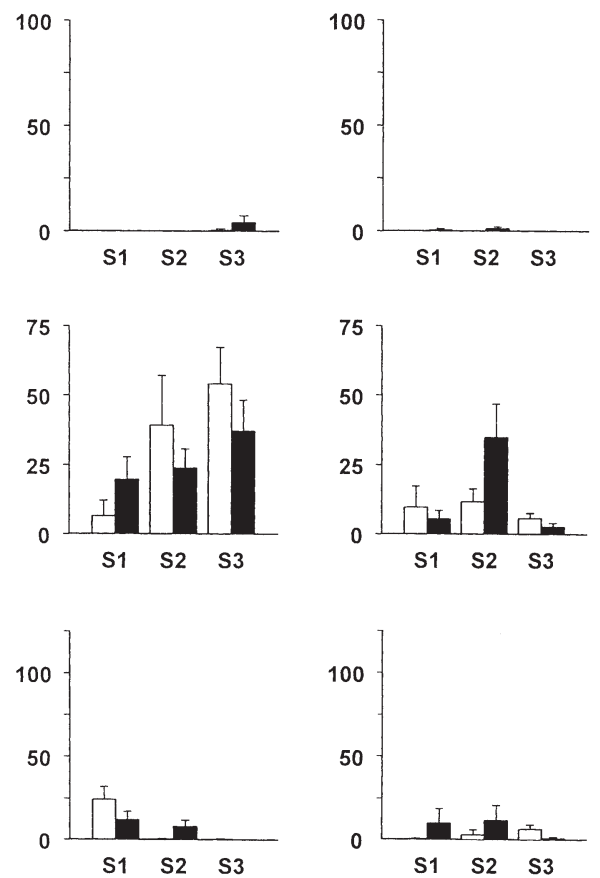

Fig. 2. Mean (+SE) cover of Enteromorpha spp. (a) and Ulva spp. (b), and mean numbers of Patelloida latistrigata (c) in mid-shore samples at Potter Point outfall and control locations several kilometres away ('Locations'), immediately adjacent to the point of discharge and at sites tens of metres away ('Sites [Outfall]') and sites within the control locations ('Sites [Control 1]' and 'Sites [Control 2]'). There were 3 sites at each location; at Potter Point, 1 site was at the point of discharge. $\mathrm{n}=4$ quadrats per site at Time $1 \square$ and Time 2 ; C1: north control location; C2: south control location; O: Potter Point outfall. (CS1: Other Site 1; C2 = Other Site 2; OS: outfall site, all within Location O); S1, S2, S3: sites within each control location

Enteromorpha spp. Link and Ulva spp. Linnaeus) and 11 taxa of gastropods (the snails Littorina unifasciata Gray, L. acutispira Smith, Turbo undulatus Lightfoot and the limpets Patelloida alticostata Angas, P. latistrigata Angas, P. mufria Hedley, Montfortula rugosa Quoy \& Gaimard, Cellana tramoserica Holton, Patella peroni Blainville, Siphonaria denticulata Quoy \& Gaimard and S. virgulata Quoy \& Gaimard) were found. Only patterns of abundance of Enteromorpha spp., Ulva spp. and Patelloida latistrigata are presented in this paper because they represent the 3 different types of pattern found in the densities of taxa in impacted and control areas at the 2 spatial scales.

\section{Patterns in abundances of taxa}

At the larger spatial scale (i.e. outfall vs. controls situated kilometres away), significantly greater cover of Enteromorpha spp. was found at the outfall than at control locations at each time of sampling (Table 1, Outfall vs. Controls; Fig. 2a). At the smaller scale, among sites on the shore, the cover of Enteromorpha spp. was much greater at the outfall than at the other sites tens of metres away (Table 1: Outfall vs others; Fig. 2a). Cover of the algae Chaetomorpha spp. and Cladophora spp. showed the same pattern as the cover of Enteromorpha at both spatial scales, but is not detailed here. So, the great increase in these taxa immediately around the outfall was responsible for the greater mean cover on the whole shore.

In contrast, at neither time was any difference in the abundance of Ulva spp. found between the shore with the outfall and the controls several kilometres away (Table 1; Fig. 2b). At the smaller scale, cover of Ulva was smaller immediately adjacent to the point of discharge than at other sites tens of metres away (Table 1: Outfall vs others; Fig. 2b). Great variability in the abundance of this taxon was also found among sites of the controls several kilometres away (Table 1; Fig. 2b), so this pattern cannot unambiguously be attributed to the outfall without sampling more sites. The numbers of the limpet Cellana tramoserica showed the same pattern as for the cover of Ulva. 
Table 1. Summaries of asymmetrical analyses comparing spatial variation in the density of intertidal taxa found at Potter Point sewage outfall and controls at 2 spatial scales. $\mathrm{n}=4$ quadrats in 3 sites at each location. $\mathrm{ns}$ : $\mathrm{p}>0.05,{ }^{*} \mathrm{p}<0.05,{ }^{* *} \mathrm{p}<0.01,{ }^{* * *} \mathrm{p}<0.001$

\begin{tabular}{|c|c|c|c|c|c|c|c|c|c|c|}
\hline \multirow[t]{2}{*}{ Source of variation } & \multirow[t]{2}{*}{ df } & \multicolumn{3}{|c|}{ Enteromorpha spp. } & \multicolumn{3}{|c|}{ Ulva spp. } & \multicolumn{3}{|c|}{ Patelloida latistrigata } \\
\hline & & MS & F-ratio & Sig & MS & $F$-ratio & Sig & MS & F-ratio & Sig \\
\hline \multicolumn{11}{|l|}{ Time 1} \\
\hline Locations & 2 & & & & & & & & & \\
\hline Outfall vs controls & 1 & 5158 & 25791 & $* * *$ & 1111 & 0.3 & $\mathrm{~ns}$ & 10296 & $25.1^{\mathrm{b}}$ & $* *$ \\
\hline Among controls & 1 & 0.2 & & & 3528 & & & 165 & & \\
\hline Sites (Locations) & 6 & & & & & & & & & \\
\hline Sites (Outfall) & 2 & & & & & & & & & \\
\hline Outfall vs others & 1 & 13086 & 362 & * & 3984 & $8.9^{\mathrm{a}}$ & * & 10375 & 0.7 & $\mathrm{~ns}$ \\
\hline Among others & 1 & 36 & & & 55 & & & 15931 & & \\
\hline Sites (controls) & 4 & 0.2 & & & 1211 & & & 410 & & \\
\hline Residual & 27 & & & & & & & & & \\
\hline Residual (outfall Sites) & 3 & 232 & & & 157 & & & 0 & & \\
\hline Residual (other Sites) & 6 & 16 & & & 447 & & & 261 & & \\
\hline Residual (control Sites) & 18 & 0.2 & & & 395 & & & 46 & & \\
\hline Cochran's test & & & $C=0.87^{* *}$ & & & $C=0.37 \mathrm{n}$ & & & $=0.35 \mathrm{~ns}$ & \\
\hline \multicolumn{11}{|l|}{ Time 2} \\
\hline Locations & 2 & & & & & & & & & \\
\hline Outfall vs controls & 1 & 8845 & 2123 & $* *$ & 39 & 0.04 & ns & 3828 & $26.0^{\mathrm{b}}$ & ${ }^{* *}$ \\
\hline Among controls & 1 & 4 & & & 950 & & & 3 & & \\
\hline Sites (locations) & 6 & & & & & & & & & \\
\hline Sites (outfall) & 2 & & & & & & & & & \\
\hline Outfall vs others & 1 & 21780 & 6970 & ** & 1893 & $5.17^{\mathrm{a}}$ & $\mathrm{p}=0.06$ & 4874 & 0.8 & ns \\
\hline Among others & 1 & 3 & 190 & & 6385 & & & & & \\
\hline Sites (controls) & 4 & 13 & & & 806 & & & 147 & & \\
\hline Residual & 27 & & & & & & & & & \\
\hline Residual (outfall Sites) & 3 & 28 & & & 0.7 & & & 1 & & \\
\hline Residual (other Sites) & 6 & 21 & & & 366 & & & 376 & & \\
\hline Residual (control Sites) & 18 & 7 & & & 252 & & & 122 & & \\
\hline Cochran's test & & & $C=0.34 \mathrm{n}$ & & & $C=0.25 \mathrm{r}$ & & & $=0.33 \mathrm{~ns}$ & \\
\hline \multicolumn{11}{|c|}{ 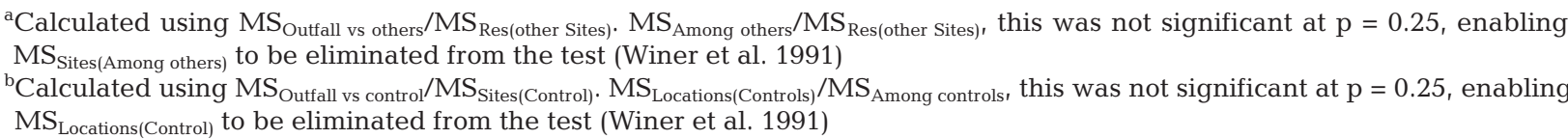 } \\
\hline
\end{tabular}

There were fewer limpets in the site near the outfall than in the 2 control sites, but no difference, on average, on that shore compared with the control locations.

The limpet Patelloida latistrigata showed yet a further pattern, in that mean density was greater, at each time, on the shore with the outfall than on the control shores several kilometres away (Table 1: Outfall vs controls; Fig. 2c). At the smaller scale, among sites on a shore, there were noticeably more $P$. latistrigata at sites away from the outfall than at the point of discharge and at sites on the control shores (Fig. 2c). A similar pattern was seen in the abundance of Siphonaria spp. The difference in the number of $P$. latistrigata between the point of discharge and the other sites at Potter Point was not statistically significant (Table 1: Outfall vs. others), because of the large variation between the 2 other sites: CS1 and CS2, 'Sites (Outfall)' in Fig. 2c.

\section{Patterns in spatial variability of abundances}

The cover of Enteromorpha was more variable among quadrats at the outfall than among quadrats at other sites at Potter Point at Time 1, but not at Time 2 (a: Table 2). In contrast, variability in abundance of Ulva (Time 2) and of Patelloida latistrigata (both times) was smaller at the 'Outfall site' than at other sites (a: Table 2). The inconsistency of patterns in the spatial variability of Enteromorpha and Ulva across sampling times appears to be due to changes in the spatial variability of these taxa at the outfall.

Comparison of variances among quadrats in the other (non-outfall) sites at the outfall location and in sites on control shores (b: Table 2) showed the cover of Enteromorpha to be more variable at the former than at the control sites at both times of sampling (b: Table 2). Thus, at both scales examined, the variability of Enteromorpha is greater close to the outfall than further away. 
Table 2. Two-tailed F-tests of variances. a: among quadrats at the outfall site versus among quadrats in other sites, all on the shore with the outfall; $b$ : among quadrats in other sites on the shore with the outfall versus among quadrats in sites on control shores; c: between the other sites on the shore with the outfall versus among sites on control shores. Out: outfall site; Oth: other sites within the outfall location; Cont: sites within control locations. Degrees of freedom and mean squares are given in Table 1. $\mathrm{ns}=\mathrm{p}>0.05 ;{ }^{*} \mathrm{p}<0.05 ;{ }^{* *} \mathrm{p}<0.01 ;{ }^{* * *} \mathrm{p}<0.001 ; \mathrm{x}$ : comparison was not made due to absence of the taxon from the outfall site

\begin{tabular}{|c|c|c|c|c|c|c|c|}
\hline Taxon & Time & \multicolumn{2}{|c|}{$\begin{array}{c}\text { a } \\
\text { Among quadrats } \\
\text { (= Residual) } \\
\text { Outfall vs other }\end{array}$} & \multicolumn{2}{|c|}{$\begin{array}{c}\text { b } \\
\text { Among quadrats } \\
(=\text { Residual }) \\
\text { Other vs control }\end{array}$} & \multicolumn{2}{|c|}{$\begin{array}{c}\text { C } \\
\text { Among sites } \\
\text { Control vs other }\end{array}$} \\
\hline \multirow[t]{2}{*}{ Enteromorpha spp. } & 1 & $* *$ & Out $>$ Oth & $* * *$ & Oth $>$ Cont & ns & \\
\hline & 2 & ns & & ${ }^{*}$ & Oth $>$ Cont & ns & \\
\hline \multirow[t]{2}{*}{ Ulva spp. } & 1 & ns & & ns & & ns & \\
\hline & 2 & $* * *$ & Out $<$ Oth & ns & & ns & \\
\hline \multirow[t]{2}{*}{ Patelloida latistrigata } & 1 & $x$ & & $* *$ & Oth $>$ Cont & $* *$ & Oth $>$ Cont \\
\hline & 2 & $* * *$ & Out $<$ Oth & ns & & $* *$ & Oth $>$ Cont \\
\hline
\end{tabular}

In contrast, the abundance of Patelloida latistrigata was less variable at other sites within the outfall location than at sites on control shores at Time 1 (b: Table 2). No pattern was evident in this measure of spatial variability for Ulva spp. at either time (Fig. 2b) or for P. latistrigata at Time 2 (Fig. 2c).

At the third spatial scale considered, i.e. among sites within a shore, Patelloida latistrigata appeared more variable between other sites on the shore with the outfall than among sites on control shores at each time of sampling. There was no pattern evident in variation among sites for Enteromorpha or for Ulva at either time of sampling.

\section{DISCUSSION}

This study has not made any major attempt to demonstrate causation between effluent and patterns of abundance. A previous study at this and other outfalls around Sydney followed changes to intertidal assemblages around outfalls following cessation of discharge of sewage (K. Banwell unpubl. data) and demonstrated that the patterns described here are attributable to the outfall (either the sewage or the freshwater discharged).

The abundance of Enteromorpha spp. was greater immediately adjacent to the point of discharge than at the 2 sites located approximately $50 \mathrm{~m}$ away, and was greater at these 3 sites proximal to the outfall than at sites on control shores several kilometres away. This pattern of greater algal abundance close to the outfall than further away at the 2 spatial scales is consistent with the gradient of decreasing abundance with increasing distance from the point of discharge previously documented for this and other outfalls (e.g. Fairweather 1990, López Gappa et al. 1990).
The influence of the outfall on the spatial variability of cover of Enteromorpha also appeared to follow a gradient about the outfall. At the first time of sampling, greater variability was found close to the outfall than further away for all 3 spatial scales examined (quadrats in the outfall and other sites on the shore with the outfall; quadrats in other sites on that shore versus among quadrats in sites on control shores; between sites on the shore with the outfall and on control shores). At the second time of sampling, variances among quadrats only differed between other sites on the outfall shore and between sites on control shores. This was due to a reduction in the spatial variability among quadrats of cover of Enteromorpha at the outfall site at the second time of sampling (28 to 232: Table 1). Thus, the algae may well be responding to some gradient of contaminants, salinity and/or temperature connected with increasing dilution of effluent with seawater with increasing distance from the point of discharge.

Patterns in the abundance and spatial variability of the other 2 taxa did, however, differ among the spatial scales of sampling and could not be following the gradient in the concentration of contaminants. The abundance of Ulva spp. was not found to differ between the outfall and control locations situated several kilometres away, but was smaller at the point of discharge than at sites tens of metres away. Similarly, at the first time of sampling there was greater variability in the cover of Ulva among quadrats at the outfall site than among quadrats in other sites on the outfall shore. There was, however, no difference in spatial variability of cover of Ulva between sites away from the point of discharge but on the same shore and sites on control shores, either for quadrats or for sites. The results may instead be due to spatial variation among sites but, formally, given the number of sites sampled, there was evidence for an impact at the smaller scale (among sites on a shore). If the putative impact of this outfall on 
intertidal assemblages had been sampled at only the larger (and more commonly sampled) spatial scale it would have been falsely concluded that the effluent had no effect on cover or variation of Ulva spp. This result is of particular concern given that Ulva spp. are frequently sampled to detect environmental impacts because of their widespread occurrence and the rapid rate at which populations can respond to change (e.g. Borowitzka 1972, Littler \& Murray 1975, May 1985, Fairweather 1990). Clearly, unless sampling is designed carefully to be at the appropriate spatial scale (or, preferably, at several spatial scales), the capacity to detect impacts will be severely impaired, if not completely lacking.

A complete reversal in the impact of the outfall on the abundance and spatial variability of Patelloida latistrigata was evident across different spatial scales of sampling. At the larger spatial scale (within several hundred metres of the outfall versus several kilometres away), a greater abundance of $P$. latistrigata was found at impacted than at control locations. At the smaller spatial scale (immediately adjacent to the point of discharge versus approximately $50 \mathrm{~m}$ away), the discharge of sewage reduced the density of this gastropod. Patterns in the spatial variability of $P$. latistrigata appeared to follow patterns of abundance. At the scale of quadrats, the abundance of this species was less variable at the outfall site than at other sites on that shore. Variances among quadrats and among sites were, however, greater at sites away from the point of discharge at Potter Point than at sites on control shores. Previous studies on effects of sewage outfalls on the abundance of gastropods (e.g. Tablado et al. 1994) have failed to detect such a reversal in impact across the 2 different spatial scales due to their assumption that abundance will follow a gradient of pollution. This study clearly demonstrates that such an assumption will not necessarily be correct.

The pattern of abundance of Patelloida latistrigata around this outfall is similar to that described for benthic macrofauna around industrial-waste and sewage outfalls (e.g. Bellan \& Bellan-Santini 1972, Anger 1975, Rosenberg 1976). Sediment in the immediate vicinity of a point of discharge was found to be devoid of benthic macrofauna. The abundance of macrofauna increased dramatically to a maximum a short distance away from the point of discharge due to extremely abundant populations of several opportunistic species. This assemblage of great macrofaunal abundance was found to have a narrow distribution, and total abundance was observed to decrease from this point with increasing distance from the source of organic material to the level found under undisturbed conditions.

This study clearly shows, as demonstrated by Raimondi \& Reed (1996), that ecological variables cannot necessarily be correlated with chemical or physical variables. Thus, the relevant scales of sampling to detect a particular impact cannot simply be implied by modelling or monitoring physical and chemical variables, as has been done in and recommended by many previous studies (e.g. Spellerberg 1991). Sampling at several scales is important, given that sampling at the wrong scale may result in failure to detect an impact and that populations may respond to disturbances in different ways at different spatial scales.

Earlier research on aspects of the biology and ecology of the study of organisms and the predicted gradients of contamination might be used to determine relevant and appropriate spatial scales for sampling. The types and spatial scales of responses of organisms to contamination are not often predictable from the available information. Under such circumstances, preliminary sampling at several spatial scales is crucial to ensure that the ecological responses to contamination are not missed or misinterpreted.

Wherever possible, attempts to identify or measure impacts should involve sampling on multiple spatial scales using a nested sampling design (see Underwood 1992). Where this is not possible due to time, cost or physical constraints of the environment in which the work is to be done, the spatial scale at which any impact is supposed to be operating must be clearly stated so that sampling is at an appropriate spatial scale. Without further study in each case, it is not possible to make a valid generalisation that a disturbance has a similar impact at any relevant spatial scale that could be sampled.

Acknowledgements. This study was supported by funds from the Australian Research Council through the Special Centre for Research on Ecological Impacts of Coastal Cities, an Australian Postgraduate Award to M.J.B. and an NSERC Research Fellowship to P.A. We thank Dr. M. G. Chapman for discussion and several anonymous referees for helpful comments and revisions.

\section{LITERATURE CITED}

Anger K (1975) On the influence of sewage pollution on inshore benthic communities in the South Kiel Bay. Part 2. Quantitative studies on community structure. Helgol Meeresunters 32:73-148

Aronson RB (1994) Scale-independent biological processes in the marine environment. Oceanogr Mar Biol Annu Rev 32: 435-460

Bellan G, Bellan-Santini D (1972) Influence of pollution on marine populations in the Marseilles region. In: Ruivo $M$ (ed) Marine pollution and sea life. FAO, Fishing News (Books), London, p 396-401

Borowitzka MA (1972) Intertidal algal species diversity and the effect of pollution. Aust J Mar Freshw Res 23:73-84

Box GEP (1953) Non-normality and tests on variances. Biometrika 40:318-335 
Chapman MG, Underwood AJ, Skilleter GA (1995) Variability at different spatial scales between a subtidal assemblage exposed to the discharge of sewage and 2 control assemblages. J Exp Mar Biol Ecol 189:103-122

Dayton PK, Tegner MJ (1984) The importance of scale in community ecology: a kelp forest example with terrestrial analogs. In: Price PW, Slobodchikoff CN, Gaud WS (eds) A new ecology: novel approaches to interactive systems. John Wiley \& Sons, New York, p 457-482

Fairweather PG (1990) Sewage and the biota on seashores: assessment of impact in relation to natural variability. Environ Monit Assess 14:197-210

Foe C, Knight A (1987) Assessment of the biological impact of point-source discharges employing asiatic clams. Arch Environ Contam Toxicol 16:39-51

Inglis G, Lincoln Smith M (1994) Choosing appropriate spatial scales for ecological monitoring programs: an estuarine case study. In: Bellwood O, Choat $\mathrm{H}$, Saxena N (eds) Recent advances in marine science and technology ' 94 . James Cook University, Townsville, Australia, p 171-180

Intergovernmental Oceanographic Commission, UNESCO (1986) IOC workshop on the biological effects of pollutants. Workshop report No. 53. UNESCO, Paris

Keough MJ, Black KP (1996) Predicting the scale of impacts: understanding planktonic links between populations. In: Schmitt RJ, Osenberg CW (eds) Detecting ecological impacts: concepts and applications in coastal habitats. Academic Press, San Diego, p 199-234

Levin SA (1992) The problem of pattern and scale in ecology. Ecology 73:1943-1967

Littler MM, Murray SN (1975) Impact of sewage on the distribution, abundance and community structure of rocky intertidal macro-organisms. Mar Biol 30:277-291

López Gappa JJ, Tablado A, Magaldi NH (1990) Influence of sewage pollution on a rocky intertidal community dominated by the mytilid Brachidontes rodriguezi. Mar Ecol Prog Ser 63:163-175

May V (1985) Observations on algal floras close to 2 sewage outlets. Cunninghamia 1:385-394

Menge BA, Olson AM (1990) Role of scale and environmental factors in regulation of community structure. Trends Ecol Evol 5:52-57

Raimondi PT, Reed DC (1996) Determining the spatial extent of ecological impacts caused by local anthropogenic disturbances in coastal marine habitats. In: Schmitt RJ, Osen-

Editorial responsibility: Roger Hughes (Contributing Editor), Bangor, Wales, UK berg CW (eds) Detecting ecological impacts: concepts and applications in coastal habitats. Academic Press, San Diego, p 179-198

Rosenberg R (1976) Benthic faunal dynamics during succession following pollution abatement in a Swedish estuary. Oikos 27:414-427

Santelices B (1990) Patterns of reproduction, dispersal and recruitment in seaweeds. Oceanogr Mar Biol Annu Rev 28:177-276

Spellerberg IF (1991) Monitoring ecological change. Cambridge University Press, Cambridge

Sydney Water (1998) Annual environment report. Sydney Water Corporation, Sydney

Tablado A, López Gappa JJ, Magaldi NH (1994) Growth of the pulmonate limpet Siphonaria lessoni (Blainville) in a rocky intertidal area affected by sewage pollution. J Exp Mar Biol Ecol 175:211-226

Underwood AJ (1992) Beyond BACI: the detection of environmental impacts on populations in the real, but variable, world. J Exp Mar Biol Ecol 161:145-178

Underwood AJ (1993) The mechanics of spatially replicated sampling programmes to detect environmental impacts in a variable world. Aust J Ecol 18:99-116

Underwood AJ (1994) On beyond BACI: sampling designs that might reliably detect environmental disturbances. Ecol Appl 4:3-15

Underwood AJ (1997) Experiments in ecology: their logical design and interpretation using analysis of variance. Cambridge University Press, Cambridge

Ward D, Saltz D (1994) Foraging at different spatial scales: Dorcas gazelles foraging for lillies in the Negev desert. Ecology 75:48-58

Warwick RM, Clarke KR (1993) Increased variability as a symptom of stress in marine communities. J Exp Mar Biol Ecol 172:215-226

Wiens JA (1989) Spatial scaling in ecology. Funct Ecol 3: 385-397

Winer BJ, Brown DR, Michels KM (1991) Statistical principles in experimental design, 3rd edn. McGraw-Hill, New York

Zmarzly DL, Stebbins TD, Pasko D, Duggan RM, Barwick KL (1994) Spatial patterns and temporal succession in softbottom macroinvertebrate assemblages surrounding an ocean outfall on the southern San Diego shelf: relation to anthropogenic and natural events. Mar Biol 118:293-307

Submitted: May 30, 2001; Accepted: January 4, 2002

Proofs received from author(s): June 4, 2002 